\title{
Extraction of a novel biopesticide obtained from agricultural weeds useful for medicinal plants
}

\author{
Manish Krishna ${ }^{1}$, Taruna Khemchandani ${ }^{1}$ and Balaji R. Raja ${ }^{2 \star}$ \\ ${ }^{1}$ Department of Biotechnology, SRM University, Kattankulathur - 603203, Tamilnadu, India \\ ${ }^{2}$ Department of Biotechnology, National Institute of Technology, Raipur - 492001, Chhattisgarh, India
}

Accepted 13 November, 2012

\begin{abstract}
The major problem faced in agriculture is the weeds and the pests. In order to remove or kill the weeds and the pests, there is a large scale use of weedicides and pesticides that leads to dual expenditure at the cost of crop maintenance. Weeds are rarely considered a priority despite the fact that all the farmers know that majority of their variable costs and time is devoted to eradicate them. The objective of the work was to derive a simple and cheap method to produce a biopesticide from agricultural weeds, in an order which could be used by the farmers. Nineteen weeds were selected, and a biopesticide was produced from them by extraction method. The produced biopesticide was tested in 5 agricultural fields against tea, paddy, maize and cabbage plants. The pesticide was highly effective against aphids, leaf folder disease, thrips, Japanese beetle, army worm and the cutworm caterpillar. The effect of the biopesticide derived from the agricultural weeds was around $\mathbf{5 0}$ to $\mathbf{7 5 \%}$ more than the conventional chemical based pesticide. The biopesticide produced by this method helps in weed eradication, lowers the cost of crop production and is helpful in getting rid of the harmful effect of chemicals on the entire ecosystem.
\end{abstract}

Key words: Weed, pest, biopesticide, eco system, agriculture.

\section{INTRODUCTION}

The problems posed by weeds and pests in Indian agriculture are quite substantial. A large scale use of weedicides and pesticides becomes unavoidable to remove or kill the weeds and pests, leading to dual expenditure at the cost of crop maintenance. Weeds are rarely considered a priority despite the fact that all the farmers know that majority of their variable costs and time is devoted to eradicate them. Most crops losses due to pests can be traced directly back to weeds, which harbor the pest as the secondary host. The eradication of weeds mainly done by the farmers is practiced in two ways: (1) mechanical removal which is performed by derooting the whole plant and (2) using weedicides which are sprayed on the weeds. Pest control has as its objective, the reduction of insects and pests, plant pathogen and weeds, to acceptable levels. But despite all the control efforts used, pest annually destroy about $35 \%$ of all crops worldwide. At the close of the twentieth century, agricultural weed management diverged in two distinct directions. In one set of farming systems, which we will call conventional, farmers rely primarily on herbicides to suppress weeds.

This approach is exemplified by the extensive maize (Zea mays L.)/soyabean (Glycine max (L.) Merr.) systems of the mid-western USA, where $>110$ million $\mathrm{kg}$ of herbicide active ingredients are applied annually to > $95 \%$ of the area planted with those two crops (Lin et al., 1995). In a second set of farming systems, which we will call low external input (LEI), herbicides are largely or entirely avoided, and weeds are suppressed largely through physical and ecological tactics. Although LEI systems occupy only a small portion of the agricultural 
landscape in most regions, they are becoming increasingly prominent as economic, regulatory and biological pressures on conventional farming systems intensify. Refinement and greater adoption of LEI practices have been proposed as ways to address low farm profitability, environmental and health risks of agrochemical exposure and shifts in populations and communities of weeds and other pests towards pesticideresistant genotypes and species (Benbrook, 1996). These concerns and expanding world markets for organic products provide important incentives for improving weed management in LEl farming systems. Owing to a longstanding paucity of weed science research relevant to LEI systems (Benbrook, 1996), strategies to improve weed management are among the top research priorities of LEI farmers (Organic Farming Research Foundation, 1998). Weed scientists should recognize the exceptional opportunity that currently exists to address the selfidentified needs of LEl farmers.

Invasive plant species pose an increasing threat to global biodiversity (Walker and Steffen, 1997). Complete success of biocontrol, where no other control methods are required, accounts for approximately one-third of all completed biological control programmes (Fowler et al., 2000). Other management options are therefore required for well over half the weeds targeted by biological control programmes. In this context, it seems remarkable how few documented examples exist where integration of biocontrol with other management options has been demonstrated to result in improved weed management (Trumble and Kok, 1980). The challenge for ecologists is to predict what combination of management strategies will be most effective, what consequences management will have on weed populations and their ability to recover, and how other components of the ecosystem respond.

The biopesticide can be extracted on a large scale using the weeds. It has a widespread application on almost all the pests. They could be used for reducing crop production cost, for repelling the mosquitoes and other insects from the water logged areas, near the drains and residential areas, can be significantly used to repel termites, and can be widely used for organic farming. Attributes of the invader and invaded community both contribute to successful invasions (Crawley, 1987; Sakai et al., 2001), so sustainable management of invaders may involve the manipulation of invaded communities and disturbance regimes, as well as direct control of the target species. For successful control, it may be necessary to change disturbance regimes or the succession trajectory of the community by creating favourable establishment opportunities for native competitors and unfavourable opportunities for weed regeneration. Empirical evidence supports the importance of land management and disturbance regimes in combination with herbivory for determining the abundance and persistence of invasive leguminous shrubs (Paynter et al., 2000; Bellingham and Coomes,
2003). The target of pest control can also be achieved by the use of some weeds that possess pesticidal properties.

\section{MATERIALS AND METHODS}

The following 19 weeds collected from crop fields were used for the production of a biopesticide.

1. Ipomoea carnea fistulosa

2. Lantana camara

3. Ricinus communis

4. Tridax procumbens

5. Ageratum conyzoides

6. Datura metel

7. Datura stramonium

8. Cassia tora

9. Amraranthus reteroflexus

10. Achyranthus aspera

11. Calotropis gigantean

12. Leucas aspera

13. Acorus calamus

14. Physalis crassifolia

15. Argemone Mexicana

16. Cyperus rotundus

17. Polygonum hydropiper

18. Wormwood

19. Cynodon dactylolon

Nineteen different weeds as listed, showing resistance to pests were collected from the crop fields in Kishankanj district, Bihar, India. The weeds were manually de-rooted and washed, this was followed by crushing. The crushed weeds were then transferred into a large vessel containing cow urine. The container was covered and the mixture was stirred occasionally for 3 to 4 days, this was left alone for 15 to 20 days. The resultant solution was then filtered. The extract was diluted (using water) in the ratio 50:50, and 2 liters of the solution was obtained, to be applied on the pest infected crops. The filtrate obtained was sent to five different agricultural farms in order to know its effect on the various pest infected crops. This obtained solution was put in the spraying machine for foliar spray. The spraying was done thrice: on day 1 , day 4 and finally on day 7 . The effect was observed and results were recorded accordingly.

\section{RESULTS AND DISCUSSION}

The biopesticide extracted was tested in 5 different agricultural farms in Kishanganj district of Bihar. The letter was received from the farms along with the relevant photographs. The biopesticide was tested on Tea, Paddy, Maize and Cabbage plants.

\section{Paddy plant}

Paddy fields infected by leaf folder disease (Figure 1) and moths (Figure 2) showed about 65 to $70 \%$ improvement. There was a gradual improvement in pest reduction, with slight improvement on the 3rd day after biopesticide was sprayed (Figure 3), better improvement on the 5th day 


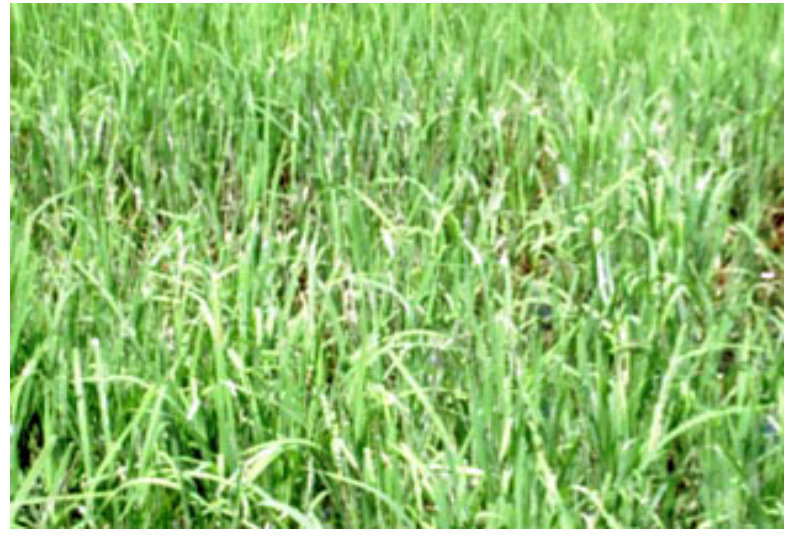

Figure 1. Paddy fields infected by leaf folder disease.

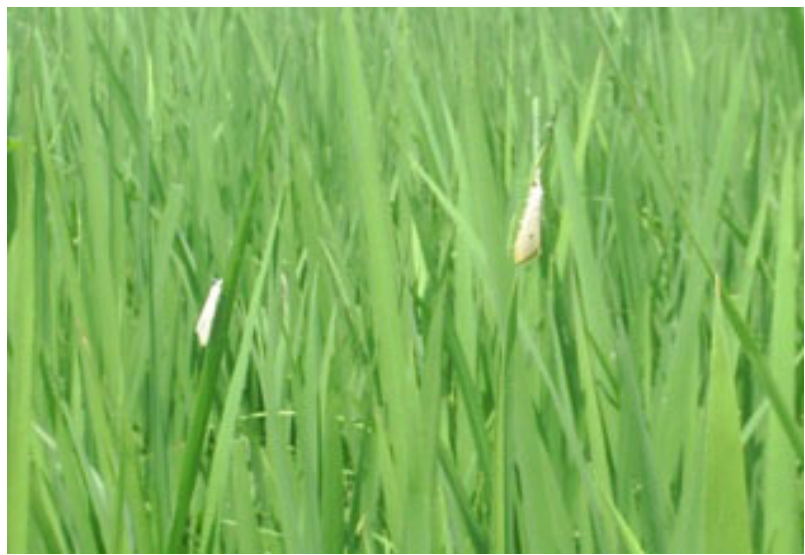

Figure 2. Paddy fields infected by moths

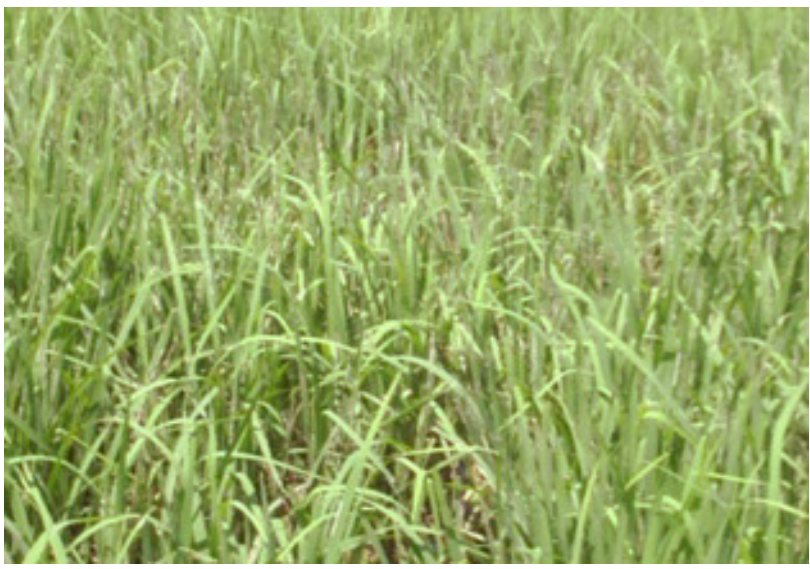

Figure 3. Paddy fields on the 3rd day of spraying with biopesticide.

(Figure 4) and even better result on the 7th day (Figure 5) After 10 days, fresh leafs were observed.

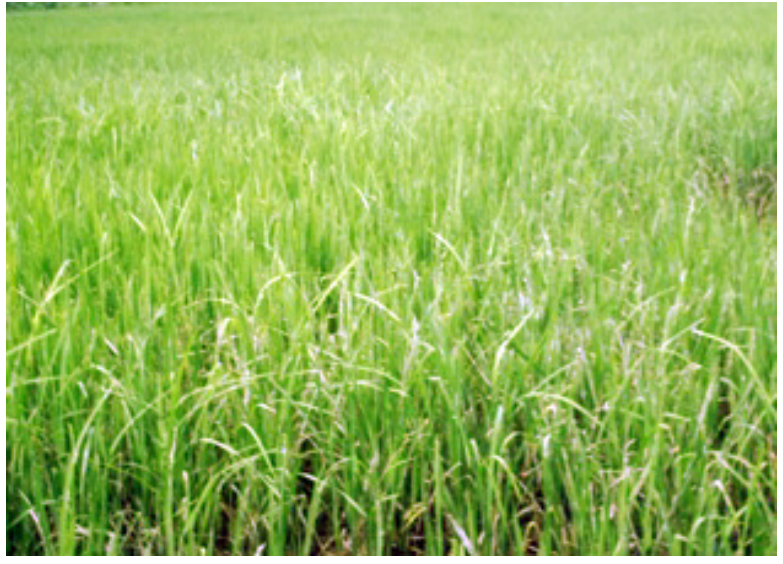

Figure 4. Paddy fields on the 5th day of spraying with biopesticide.

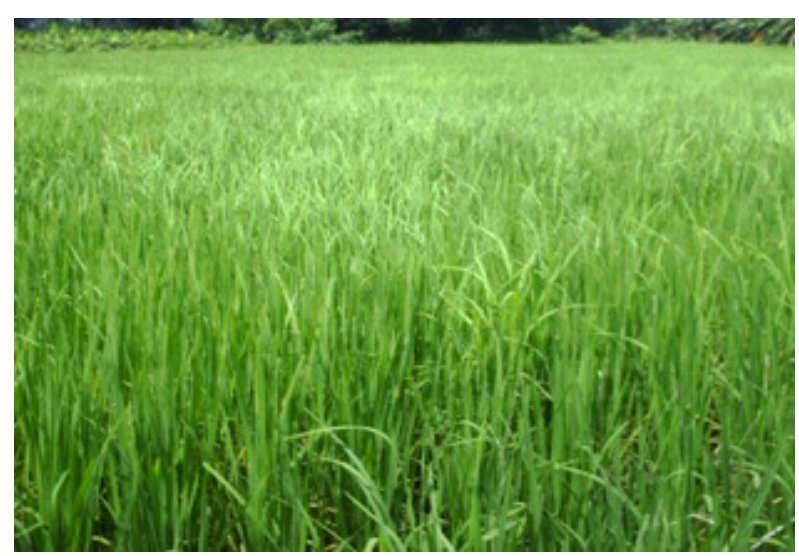

Figure 5. Paddy fields on the 7th day of spraying with biopesticide

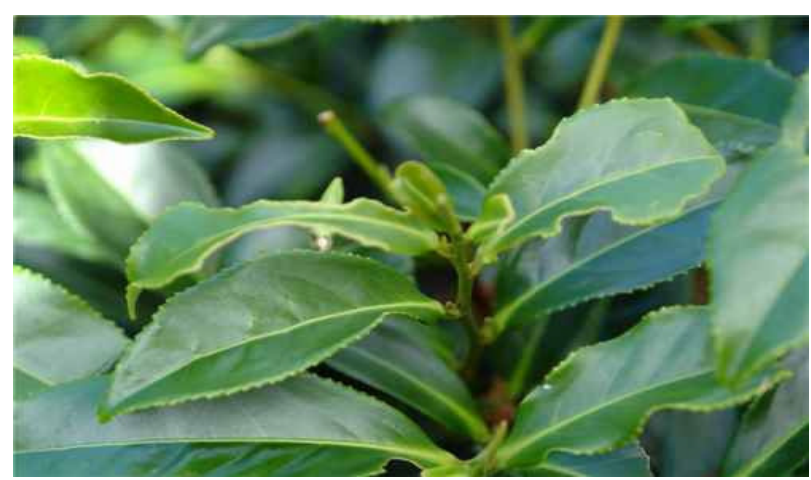

Figure 6. Tea crops infected by aphids.

\section{Tea plant}

Tea crops infected by aphids (Figure 6) and heleopeltis (Figure 7) showed maximum effect. On the 10th day of spraying of biopesticide, about 75 to $80 \%$ pests were 

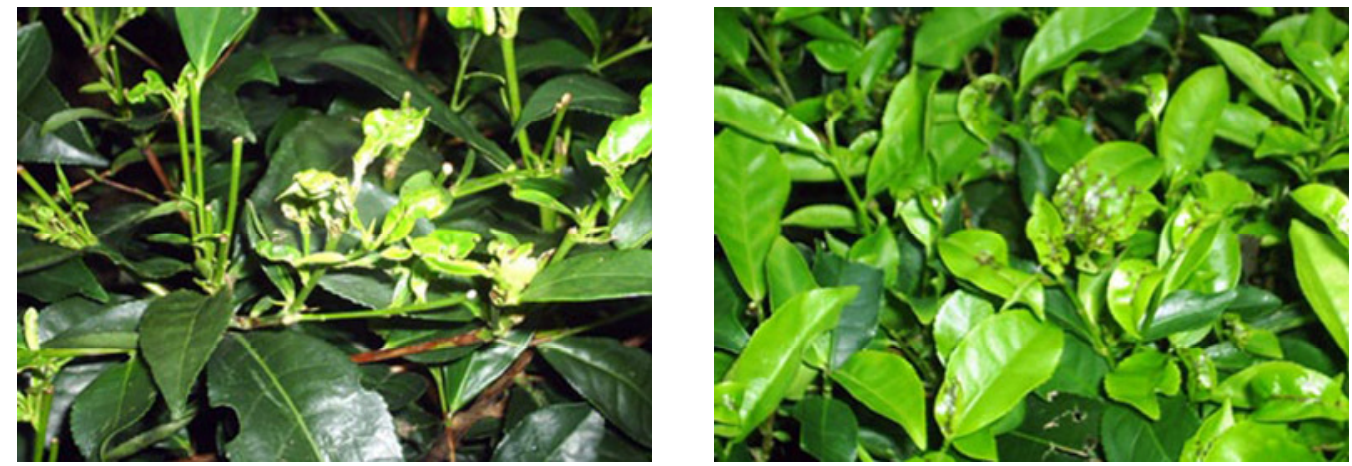

Figure 7. Tea crops infected by heleopeltis.
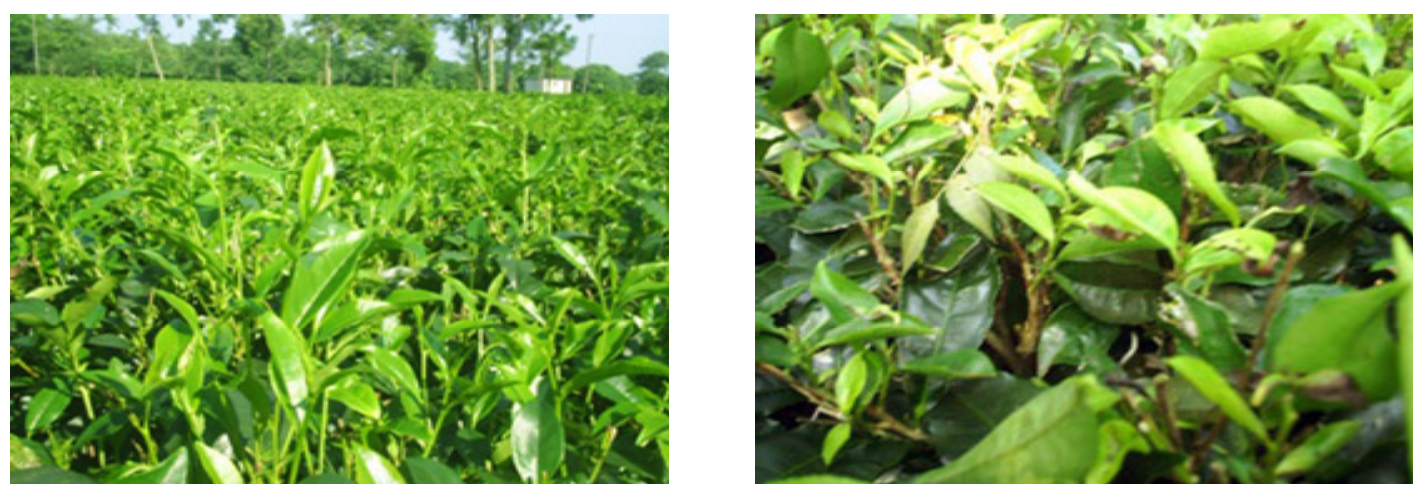

Figure 8. Tea fields on the 10th day of spraying with biopesticide.

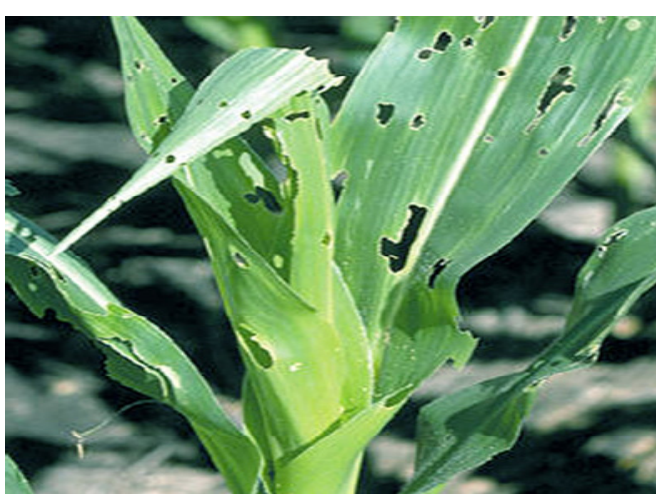

Figure 9. Maize plants affected by Japanese beetle.

eradicated and new leafs started budding (Figure 8). The effect of biopesticide recorded by the reduction of leaf rot and loss of green colour was evident.

\section{Maize plant}

Maize plants affected by Japanese beetle (Figure 9), thrips (Figure 10), army worm (Figure 11) and grasshopper (Figure 12) were selected for the test. After 3

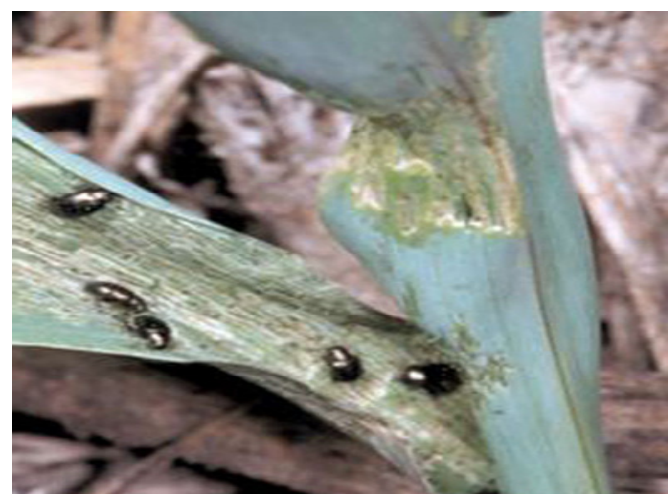

doses of the biopesticide, 70 to $75 \%$ improvement was observed (Figure 13). The plant also showed regeneration of new plant leaves after the use of biopesticide continuously for 7 days.

\section{Cabbage plant}

In the cabbage field, the cabbage with less infection of cutworm caterpillar were tested; some plants treated with 


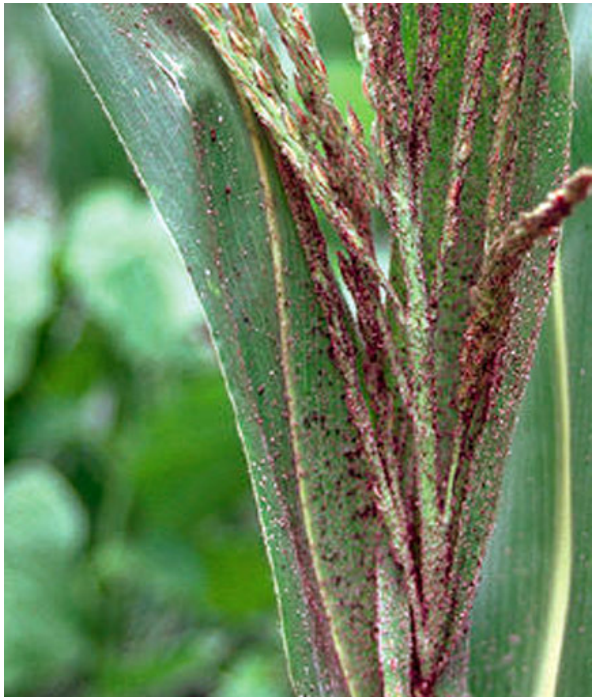

Figure 10. Maize plants affected by thrips.

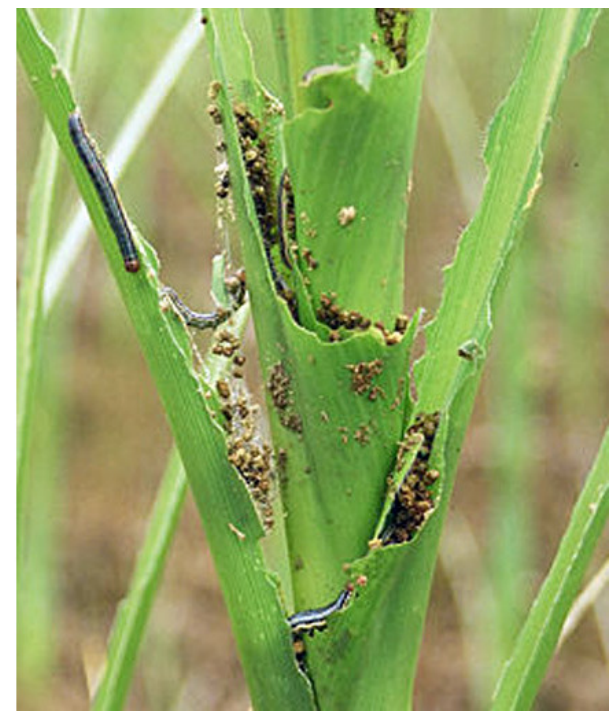

Figure 11. Maize plants affected by army worm.

the biopesticide thrice were cured completely (Figure 15), and the untreated plants were completely eaten by the worms (Figure 14).

Non-chemical weed control is generally regarded as less cost-effective compared with chemical weed management. This is mainly due to the fact that all nonchemical weed control methods require repeated treatments and may be labour-intensive. For example, in thermal weed control, the driving speed usually needs to be quite low to achieve sufficient weed control and reduce weed regrowth. Efforts are made to increase effectiveness of the most used methods and thereby lower the costs. However, one of the main shortcomings of non-chemical weed control on cash crops thus far is a

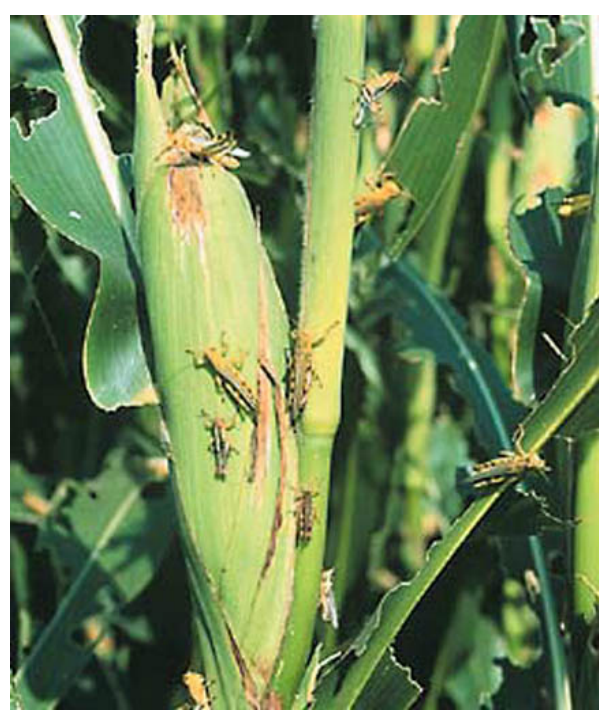

Figure 12. Maize plants affected by grasshopper.

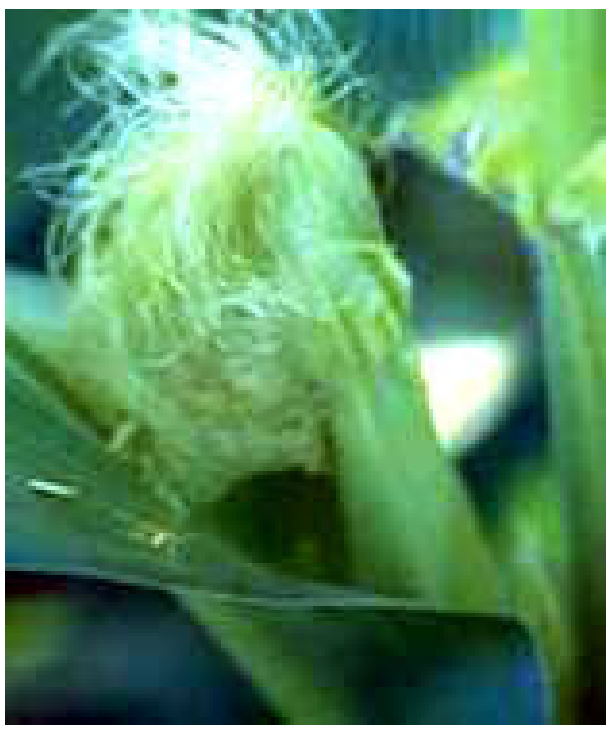

Figure 13. Maize crop after 10 days of spraying with biopesticide.

lack of proper definition of efficiency of the weed control methods. The literature study reveals a need to standardize the descriptions of experiments to make them comparable. The effect of biopesticide was quite evident on all the crops it was tested upon. The effect was visible from the 3rd day, increased evidently on the 5th day and peaked on the 7th day. Its action against cash crops and other crops is an important feature which previous studies (Ascard, 1988; Benvenuti, 2004; Bond and Grundy, 2001; Chatizwa, 1997) have not dealt with. The concept of using agricultural weeds based system against weeds in case of cash crops and other crops is a new concept in Indian scientific community. 


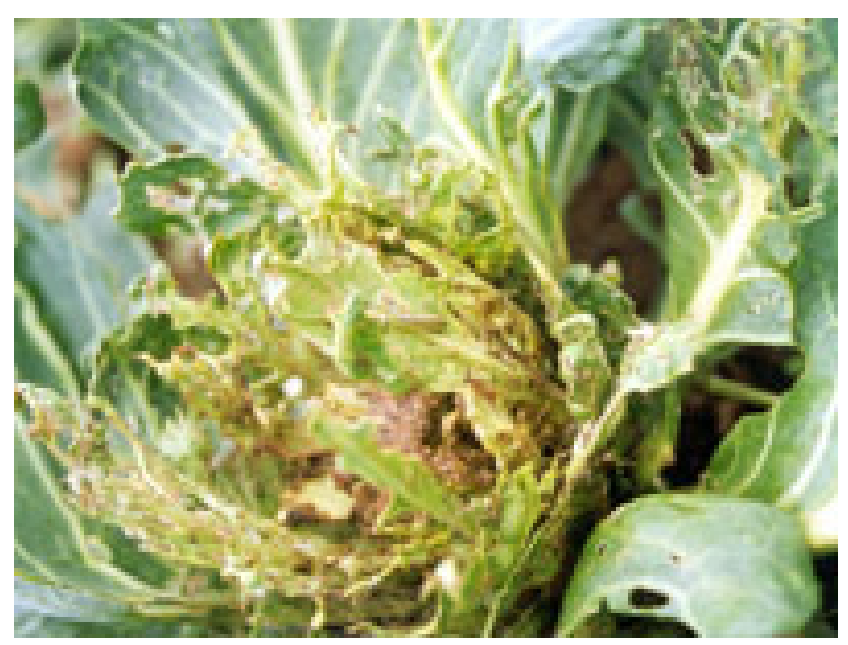

Figure 14. Untreated plants which were completely eaten by the worms.

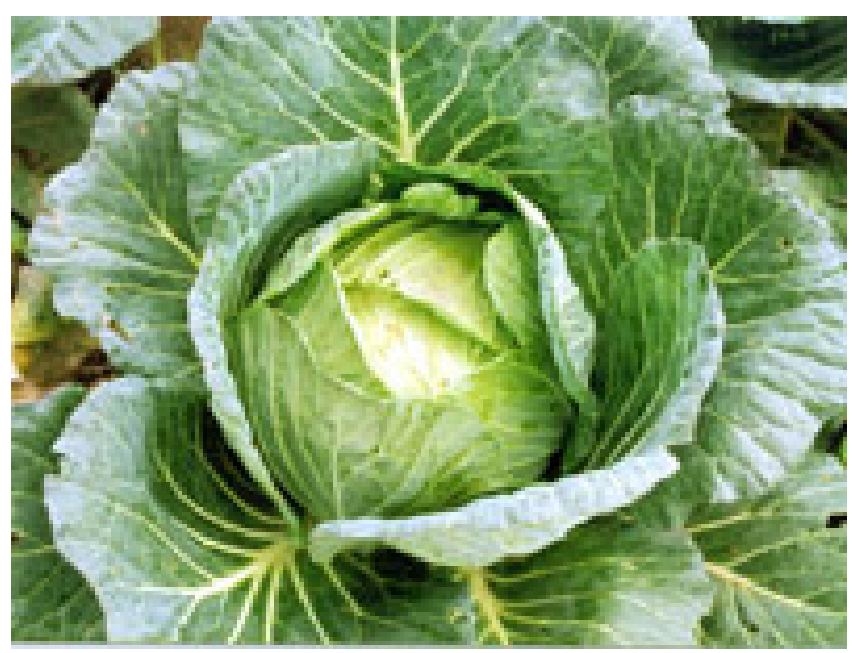

Figure 15. Cabbage after 10 days of spraying with biopesticide

\section{Conclusion}

The idea behind the work was to use the unwanted harmful weeds for making biopesticide which involves almost no expense, and make the extraction process so simple that every farmer can prepare it by himself. It is also taken into account that a considerable amount of pesticide can be extracted without the use of sophisticated equipment and complex methodology. This work deals with making use of the expenses of eradicating the weeds and hence utilizing it to lower the cost of crop production. This will greatly prove to be helpful in getting rid of the harmful effect of chemicals on the entire ecosystem.

Extraction of biopesticide using the technique, does not involve any expensive solvent; rather it just requires cow urine as the solvent, which is readily available to the farmers. The plants selected as the raw material are available in all the agricultural fields in abundance, so there is no extra expenditure on cultivating and maintaining the raw materials separately. The technique utilizes the labour cost spent on de-rooting the weeds and crushing them, as the same weed is being utilized profitably for manufacturing the biopesticide. Most importantly, these weeds are abundantly seen growing in and around the agricultural fields, wastelands and along the roadsides, they may be used profitably by saving the amount spent on pesticides and weedicides, besides managing the weeds. The cost of this biopesticide is almost nil as compared to synthetic pesticides and weedicides being used these days.

Unlike the synthetic pesticides and weedicides, this does not harm the predaceous and parasitic insects useful to the plants. Since the biopesticide extracted is plant based and not synthetic, there is no chance for any residue to be left in the food stuff. The biopesticide obtained by this method has a significant effect on a variety of pests which are commonly found on a number of crops, so this single biopesticide can be applied to almost all the crops. The extract obtained is biodegradable and hence is eco-friendly.

\section{ACKNOWLEDGEMENTS}

We would like to thank the farmers of Kishanganj, Bihar, India for allowing us to carry out the study on their agricultural fields. The help of Mr. Bhagwat Prasad Singh, Ex-District agriculture officer, Kishanganj, Bihar in identifying the pests is appreciable.

\section{REFERENCES}

Ascard J (1988). Thermal Weed Control. Flaming for weed control and crop defoliation (OT: Termisk ogräsbekämpning. Flamning för ogräsbekämpning och blastdödning). Department of Agricultural Engineering, Swedish University of Agricultural Sciences. Alnarp, Sweden. Report 130 [In Swedish with English summary].

Bellingham PJ, Coomes DA (2003). Grazing and community structure as determinants of invasion success by Scotch broom in a New Zealand montane shrubland. Divers. Distrib. 9:19-28.

Benbrook CM (1996). Pest management at the crossroads. Consumers Union, Yonkers, NY, USA.

Benvenuti S (2004). Weed dynamics in the mediterranean urban ecosystem: ecology, biodiversity and management. Weed Res. 44:341-354.

Bond W, Grundy AC (2001). Non-chemical weed management in organic farming systems. Weed Res. 41:383-405.

Chatizwa I (1997). Mechanical Weed Control: The Case of Hand Weeders. In: Brighton Crop Protection Conference- Weeds 203-208.

Crawley MJ (1987). What makes a community invasible? Colonization, Succession and Stability. Blackwell, Oxford, UK. pp. 429-453.

Fowler SV, Syrett P, Hill RL (2000). Success and safety in the biological control of environmental weeds in New Zealand. Austral Ecol. 25:553-562.

Lin BH, Padgitt M, Bull L, Delvo H, Shank D, Taylor H (1995). Pesticide and fertilizer use and trends in US agriculture. Agricultural Economic 
Report No. 717. Economic Research Service, US Department of Agriculture, Washington, DC, USA. Organic farming research foundation (OFRF). (1998). Third Biennial National Organic Farmers Survey. OFRF, Santa Cruz, CA, USA.

Paynter Q, Fowler SV, Memmott J, Shaw RH, Sheppard AW (2000). Determinants of broom (Cytisus scoparius (L.) Link) abundance in Europe. Plant Prot. Q. 15:149-155.

Sakai AK, Allendorf FW, Holt JS, Lodge DM, Molofsky J, Baughman S, Cabin RJ, Cohen JE, Ellstrand NC, McCauley NE, O'Neil P, Parker IM, Thompson JN, Weller SG (2001). The population biology of invasive species. Ann. Rev. Ecol. Syst. 32:305-332.
Trumble JT, Kok LT (1980). Integration of a thistle-head weevil and herbicides for integrated control of Carduus thistles. Weed Res. 20:57-64

Walker B, Steffen W (1997). An overview of the implications of global change for natural and managed terrestrial ecosystems. Conservation Ecology

Online, 